\title{
REVERSION IN SHEEP
}

\author{
L. L. Heller
}

Animal Husbandman in Sheep and Goat Investigations, Bureau of Animal Industry, Washington, D.C.

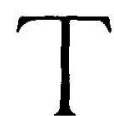

HOSE familiar with sheep know that the Rambouillet breed, a French improvement on the Spanish Merino, is one of the most highly improved of all sheep. Its color is pure white.

On April 4, 1915, there were dropped in the United States Department of Agriculture experiment flock at Laramie, Wyo., twin ewe Rambouillet lambs. The one was an ordinary lamb in all respects; the other was marked as the accompanying photograph shows-the ventral part of the body, the legs, the lower part of the neck, the face with the exception of a bar between the eyes, and the inside of the ears being black.

The fine-wools have been improved as long and probably breed as true as any of the existing breeds of sheep. Yet this is not the first appearance among them of the pattern here noted. Markings very similar to these have also been seen in black sheep of other breeds. If this color pattern had occurred but once it would have no special significance and could be considered a mutation or sport, but occurring a number of times as it has it suggests the possibility of reversion to the markings of some original forebear, who existed perhaps thousands of years ago.

The markings of the Barbados or woolless sheep are sometimes after this same pattern, and it has been noted in crosses of the Southdown and Barbados too. The Barbados being an unimproved sheep having coarse brown and black hair with a small amount of wool beneath, makes the question pertinent as to whether our improved breeds could have come from a similar type, and whether this character has for the most part been latent during the past several centuries and cropped out only at intervals.

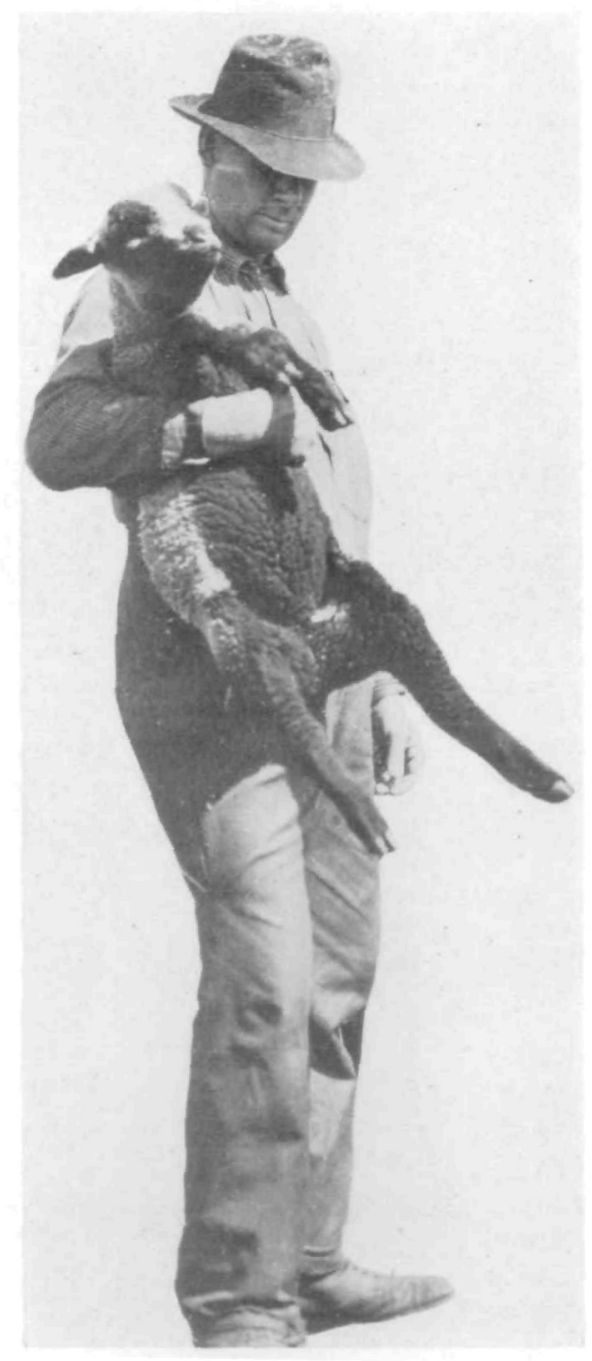

\section{WHITE IAMB'S TWIN}

The occasional appearance of this color pattern in highly improved breeds indicates that it may represent the markings of the ancestor of modern domesticated sheep. (Fig. 12.) 